\title{
Article \\ Color Stability of CAD/CAM Interim Material for Long-Term Fixed Dental Prostheses vs. Conventional Materials after Immersion in Different Staining Solutions
}

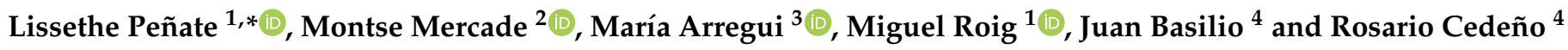 \\ 1 Department of Restorative Dentistry, Universitat Internacional de Catalunya, Sant Cugat del Vallès, \\ 08195 Barcelona, Spain; mroig@uic.es \\ 2 Department of Dentistry, Biomedical Research Institute (IDIBELL), Universitat de Barcelona, \\ 08907 Barcelona, Spain; montsemercade@ub.edu \\ 3 Department of Dentistry, Universitat Internacional de Catalunya, Sant Cugat del Vallès, \\ 08195 Barcelona, Spain; mariaarregui@uic.es \\ 4 Department of Integrated Dentistry, Universitat Internacional de Catalunya, Sant Cugat del Vallès, \\ 08195 Barcelona, Spain; jbasilio@uic.es (J.B.); rcedeno@uic.es (R.C.) \\ * Correspondence: lissethe@uic.es
}

check for

updates

Citation: Peñate, L.; Mercade, M.; Arregui, M.; Roig, M.; Basilio, J.; Cedeño, R. Color Stability of CAD/CAM Interim Material for Long-Term Fixed Dental Prostheses vs. Conventional Materials after Immersion in Different Staining Solutions. J. Compos. Sci. 2021, 5, 106. https://doi.org/10.3390/jcs5040106

Academic Editor: Masao Irie

Received: 19 March 2021

Accepted: 12 April 2021

Published: 13 April 2021

Publisher's Note: MDPI stays neutral with regard to jurisdictional claims in published maps and institutional affiliations.

Copyright: (c) 2021 by the authors. Licensee MDPI, Basel, Switzerland. This article is an open access article distributed under the terms and conditions of the Creative Commons Attribution (CC BY) license (https:/ / creativecommons.org/licenses/by/ $4.0 /)$.

\begin{abstract}
The color stability of interim computer-aided design and computer-assisted manufacturing (CAD/CAM) materials has not been exhaustively investigated. The aim of this study was to compare the translucency (TP) and contrast ratio (CR) of CAD/CAM blocks and conventional interim materials, as well as the effects of varnish application and tooth-brushing on color stability after immersion in different staining solutions. Four hundred and eighty specimens were fabricated with four different interim materials $(n=120)$ and were divided into three experimental, and one control group $(n=30)$. The color measurements were taken at the initial time (T0), $24 \mathrm{~h}$ (T1), 7 days (T2), and 30 days (T3) after immersion in different solutions. CIEDE2000 $\left(\Delta \mathrm{E}_{00}\right)$ values were analyzed with ANOVA and Fischer's LSD test with a 95\% confidence interval. The relationship between TP and CR was analyzed with a Pearson correlation. All interim materials showed a significant difference $(p<0.05)$ in color change after 30 days. Results showed that polyethyl methacrylate resins (PEMA) had the highest stability over time. The TP and CR were statistically significant $(p<0.05)$. It was observed that brushing improved the color stability but the $\Delta \mathrm{E}_{00}$ were the highest when the varnish alone or varnish and brushing were used, except in the bis-acryl group, in which varnish and brushing decreased the color stainability.
\end{abstract}

Keywords: color stability; CAD/CAM manufacturing; provisional restoration; varnish; brushing

\section{Introduction}

Interim materials should have appropriate mechanical, biological and aesthetic properties until the cementation of the definitive restoration [1-4]. Powder and liquid methacrylate resins and paste-paste composite resin-based materials have been used in recent years to manufacture interim restorations [5,6]. These materials can be polymerized by different reactions (chemical, light or dual reactions) that are activated by one or several initiators (benzoyl peroxide activated by a tertiary amine or camphorquinone) $[1,5]$. A number of interim resins are used in clinical practice; the most widely used are polymethyl methacrylate resins (PMMA), polyethyl methacrylate resins (PEMA), and resins based on multifunctional methacrylic acid esters (bis-acryl) [4,6].

One of the drawbacks of interim materials when exposed to the oral environment is their propensity to change color. The degree of color change is affected by exogenous and endogenous factors. Exogenous factors include patient habits, such as diet, tooth brushing or staining solutions, namely coffee, red wine, and black tea, among others. Endogenous factors include the initiator systems, polymerization, matrix composition, 
particle size, hardness, water sorption, hydrolysis, oxidation of the unreacted carbon double bonds [6-14], and surface roughness [15]. In order to overcome some of the problems related to the amount of powder and liquid or paste-paste mixed, manufacturers have recently introduced blocks for interim restorations to computer-aided design and computerassisted manufacturing (CAD/CAM) [16]. These blocks are mainly based on polymethyl methacrylates (PMMAs), which are industrially polymerized at high pressure and temperature, a process that significantly increases fracture load compared with conventional interim materials [17-19].

Considering the increase in surface roughness and the decrease in material brightness with tooth brushing, which affect the aesthetic quality of the restoration [20-22], some studies have proposed the use of sealant agents or varnish to cover the interim restoration surfaces to fill the irregularities in order to reduce porosity, increase wear resistance, and reduce the color stainability of the material [23-28]. However, a recent study suggested that a resin sealant may provide adequate protection for surfaces in the short term, but repeated applications are necessary for surfaces requiring protection over the longer term [29].

Research findings have pointed to qualitative and quantitative approaches to evaluate color differences. Qualitative methods are based on a subjective comparison of the specimen with a shade guide, while quantitative evaluations use a spectrophotometer to prevent bias due to human perception limits $[1,7,11,30]$. Several dental studies of color have applied the parameters of the Commission Internationale de l'Eclairage Color System (CIE). According to the CIELAB system, color relates to the proportions of the three basic colors: red, blue and green $[1,31]$. A spectrophotometer expresses measurements in terms of three coordinate values $\left(L^{*}, a^{*}, b^{*}\right)$. The $L^{*}$ coordinate represents the brightness; the $a^{*}$ value represents red or green chroma; and the $b^{*}$ value represents the yellow or blue chroma [1]. The CIELAB formula has been the classical parameter for color measurements. However, in order to analyze color stability with better adjustment, acceptability, and human perceptibility, some authors have recommended using the CIEDE2000 $\left(\Delta \mathrm{E}_{00}\right)$ instead of the CIELAB $(\Delta \mathrm{Eab})$ color-difference formula [32-34] The CIEDE2000 formula was published by CIE in 2001; it reinforces the conceptual developments of the Munsell system by using concepts of lightness, chroma, and hue, with an interaction between chroma and hue, providing much better fits for the experimental data characterized by small color differences [34-37].

In addition, other researchers have reported color parameters to evaluate translucency and opacity, such as the translucency parameter (TP) and contrast ratio (CR), both of which are based on CIE colorimetry. Translucency is known as the state between complete transparency and complete opacity, which occurs when a light beam passes through the material and part of the light is transmitted and reflected through the object. If the material is completely opaque $\mathrm{TP}=0$, and the light passes completely through the object, translucency will be greater [38-44]. A contrast ratio (CR) is defined as the ratio of the luminance of the brightest color (white) to that of the darkest color (black), resulting in the capacity of the material itself to hide a background [11,40]. This parameter depends upon the thickness of the material and the reflectance of the background [42-44]. Little research has been published comparing the color stability of CAD/CAM interim blocks with conventional interim materials. Furthermore, to our knowledge, no studies have evaluated the effect of brushing and varnish protection over these materials when they are immersed in staining solutions. The aim of this study was to compare the translucency and contrast ratio between CAD/CAM blocks and conventional interim materials, as well as the effect of varnish application and tooth-brushing on color stability after immersion in different staining solutions. Therefore, the two null hypotheses of the study were that: 1 . No difference would be found in color stability between CAD/CAM blocks and conventional interim materials after being immersed in different staining solutions for four weeks; and 2. Varnishing and brushing do not influence the color stability of the material. 


\section{Materials and Methods}

Three interim materials for the direct technique and one material for the CAD/CAM technique were used to fabricate four hundred and eighty specimens in accordance with the manufacturer's recommendations, and these were divided into three experimental groups (brush $(n=30)$; varnish $(n=30)$; and brush-varnish $(n=30))$ and one control group (without brush and varnish $(n=30)$ ) (Table 1 ). The sample size was determined by using sample size and power calculator software (GRANMO; Institut Municipal d'Investigació Mèdica, Barcelona, Spain). Figure 1 shows a diagram of the study design.

Table 1. Provisional materials used in the study.

\begin{tabular}{|c|c|c|c|c|c|c|}
\hline \multirow{2}{*}{$\begin{array}{l}\text { Dental Materials } \\
\qquad(n)^{*}\end{array}$} & \multirow{2}{*}{$\begin{array}{l}\text { Product Name } \\
\text { (Manufacturer) }\end{array}$} & \multirow{2}{*}{ Composition ** } & \multicolumn{3}{|c|}{ Groups } & \multirow{2}{*}{$\begin{array}{c}\text { Batch } \\
\text { Numbers }\end{array}$} \\
\hline & & & Code & Brushing & $\begin{array}{c}\text { Varnish } \\
\text { (Easy Glaze) }\end{array}$ & \\
\hline $\begin{array}{l}\text { Bis-acryl } \\
(n=120)\end{array}$ & $\begin{array}{c}\text { Structur } 3 \\
(\text { VOCO GmbH) }\end{array}$ & $\begin{array}{l}\text { Urethane dimethacrylate (UDMA), } \\
\text { bisphenol A-glycidyl methacrylate } \\
\text { (Bis-GMA), benzoyl peroxide. }\end{array}$ & $\begin{array}{l}\text { S3 } \\
\text { S3B } \\
\text { S3V } \\
\text { S3BV }\end{array}$ & $\begin{array}{l}\mathrm{NO} \\
\mathrm{YES} \\
\mathrm{NO} \\
\mathrm{YES}\end{array}$ & $\begin{array}{l}\mathrm{NO} \\
\mathrm{NO} \\
\mathrm{YES} \\
\mathrm{YES}\end{array}$ & 1212333 \\
\hline $\begin{array}{l}\text { Polyethyl } \\
\text { methacrylate } \\
\quad(n=120)\end{array}$ & $\begin{array}{c}\text { Trim } \\
\text { (Bosworth) }\end{array}$ & $\begin{array}{l}\text { P: ethyl methacrylate pre-polymers, } \\
\text { benzoyl peroxide, pigments, } \mathrm{TiO}_{2} \text {. } \\
\text { L: isobutyl methacrylate, di-butyl } \\
\text { phthlate, dimethyl-p-toluidine. }\end{array}$ & $\begin{array}{c}\text { T } \\
\text { TB } \\
\text { TV } \\
\text { TBV }\end{array}$ & $\begin{array}{l}\mathrm{NO} \\
\mathrm{YES} \\
\mathrm{NO} \\
\mathrm{YES}\end{array}$ & $\begin{array}{l}\mathrm{NO} \\
\mathrm{NO} \\
\mathrm{YES} \\
\mathrm{YES}\end{array}$ & $\begin{array}{l}\text { P: 1206-284 } \\
\text { L: 1206-286 }\end{array}$ \\
\hline $\begin{array}{l}\text { Polymethyl } \\
\text { methacrylate } \\
\quad(n=120)\end{array}$ & $\begin{array}{l}\text { DuraLay Crown } \\
\text { \&- Bridge } \\
\text { (Reliance) }\end{array}$ & $\begin{array}{l}\text { P: benzoyl peroxide, dialkyl phthalate, } \\
\text { residual monomers, titanium dioxide, } \\
\text { mineral pigment, disazo pigment. } \\
\text { L: methyl methacrylate. }\end{array}$ & $\begin{array}{l}\text { DL } \\
\text { DLB } \\
\text { DLV } \\
\text { DLBV }\end{array}$ & $\begin{array}{l}\mathrm{NO} \\
\mathrm{YES} \\
\mathrm{NO} \\
\mathrm{YES}\end{array}$ & $\begin{array}{l}\mathrm{NO} \\
\mathrm{NO} \\
\mathrm{YES} \\
\mathrm{YES}\end{array}$ & $\begin{array}{l}\text { P: } 092611 \\
\text { L: } 091411\end{array}$ \\
\hline $\begin{array}{l}\text { Polymethyl } \\
\text { methacrylate blocks } \\
\text { for CAD/CAM } \\
(n=120)\end{array}$ & $\begin{array}{c}\text { Telio CAD } \\
\text { (Ivoclar Vivadent) }\end{array}$ & Polymethyl methacrylate (PMMA) & $\begin{array}{l}\text { TC } \\
\text { TCB } \\
\text { TCV } \\
\text { TCBV }\end{array}$ & $\begin{array}{l}\text { NO } \\
\text { YES } \\
\text { NO } \\
\text { YES }\end{array}$ & $\begin{array}{l}\text { NO } \\
\text { NO } \\
\text { YES } \\
\text { YES }\end{array}$ & $\mathrm{R} 29681$ \\
\hline
\end{tabular}

P, powder; L, liquid. * 120 specimens per material were subdivided into groups of 30 specimens $(n=30) .{ }^{* *}$ Information provided by the manufacturers' safety data sheets. CAD/CAM: computer-aided design and computer-assisted manufacturing.

A stainless steel mold was used to make the interim material specimens for the direct technique. The mold was held between two glass slides, which were gently pressed together to eliminate excess material. Each direct technique specimen had a diameter of 10 $\pm 0.1 \mathrm{~mm}$ and a height of $2 \pm 0.05 \mathrm{~mm}$, and blocks of polymethyl methacrylate (Telio CAD; Ivoclar Vivadent, Schaan, Liechtenstein) were cut into $2 \mathrm{~mm}$ slices with a $\frac{1}{2}$ inch $(12.7 \mathrm{~mm})$ diamond specimen with the Isomet 1000 Precision Saw (Buehler, Esslingen am Neckar, Germany).

Once the specimens had been made, they were polished on the edges only with grit sandpaper (P.320; Hitech Europe MP Series, Corsico, Italy) at $50 \mathrm{rpm}$. Then, the specimens were calibrated by using a digital calibrator to verify the size to $2 \pm 0.05 \mathrm{~mm}$ thickness in order to achieve standardization. Finally, a small mark was made on the surface of the specimen to identify the same side for the color measurements. Varnish (Easy Glaze; VOCO GmbH, Cuxhaven, Germany) was applied over the surface of half of the specimens following the manufacturer's instructions.

Afterwards, five specimens per experimental group and staining solution were placed into 24-well cell culture plates, immersed in distilled water for rehydration and then left in a stove (Memmert) at $37{ }^{\circ} \mathrm{C}$ for $24 \mathrm{~h}$. The specimens were then dried with gauze and the baseline color was measured (T0) with the spectrophotometer (SpectroShade; Micro-Dental Spectrophotometer MHT;Arbizzano di Negar, Italy). The $\mathrm{pH}$ of the solution was measured during each solution replacement to verify its quality, and the specimens were then immersed in $2 \mathrm{~mL}$ staining solutions (Table 2). Before each measurement, the spectrophotometer was calibrated according to the manufacturer's instructions, by using the calibration supply and during measurements of each specimen. The color was measured 
in a black room without windows using black and white backgrounds to minimize the influence of external light on the borders of each specimen.

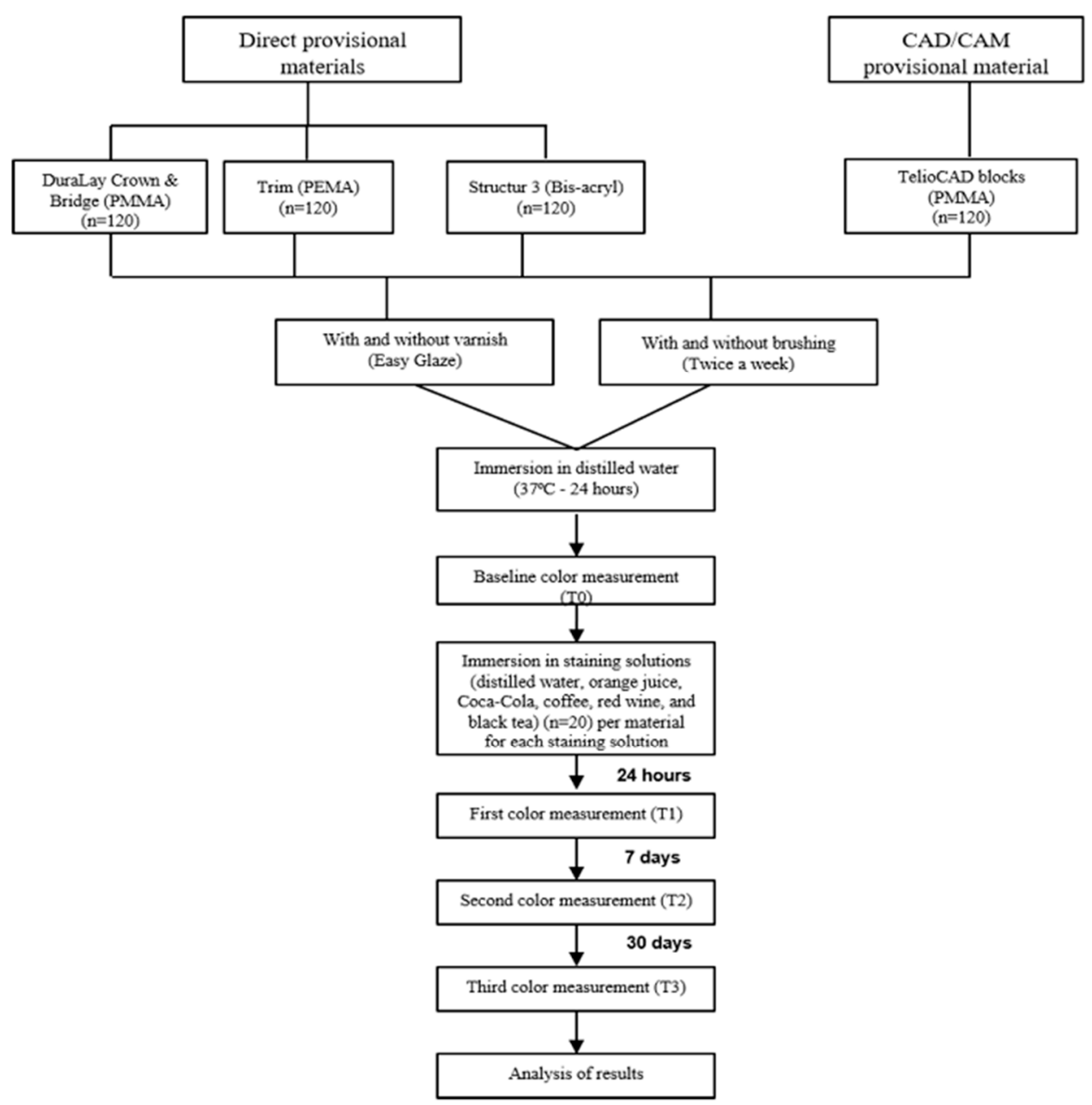

Figure 1. Diagram of the study design.

Table 2. Staining solutions used in the study.

\begin{tabular}{cccc}
\hline Scheme $(n) *$ & pH ${ }^{* *}(\mathbf{S D})$ & Abbreviation \\
\hline Distilled water $(n=20)$ & SOSMI S.A, Spain & $6.73(0.62)$ & DW \\
Orange juice $(n=20)$ & Pascual, Spain & $3.77(0.19)$ & OJ \\
Black tea $(n=20)$ & Classics English Breakfast Tea, & $5.03(0.25)$ & BT \\
Coffee $(n=20)$ & Twining, England & $4.83(0.11)$ & CF \\
Red wine $(n=20)$ & Nescafé Classic, Nestlé, Spain & $3.50(0.10)$ & RW \\
Coca-Cola $(n=20)$ & Don Simon, Spain & CC
\end{tabular}

* $(n=20)$ specimens per material in each solution. ${ }^{* *} \mathrm{pH}$ is a mean of values obtained during each solution replacement. SD: standard deviation.

\subsection{Color Evaluation}

Color measurements were measured with the same procedure before staining (T0) and after immersion in staining solutions after $24 \mathrm{~h}$ (T1), 7 days (T2), and 30 days (T3). Twice a week, the staining solution was replaced, and half of the whole specimen was brushed for $10 \mathrm{~s}$ with an electric toothbrush (Oral-B Professional Care Triumph 5000) impregnated with Colgate toothpaste (Colgate-Palmolive); each solution had its own brush head. Silicone holders were used to fix the specimens and the toothbrush in the same horizontal positions. 
The brush operated at 8800 oscillations-rotations per minute and 40,000 pulsations per minute [26].

The same protocol of changing the staining solutions twice a week was followed for the duration of this study.

Each specimen with a black background was analyzed by using the SpectroShade program. The image was opened and a contour of $300 \mu \mathrm{m}$ was established with the metric tool; this same tool was used to locate the center of the specimen. The analysis was undertaken following the same steps; in this way, the procedure was standardized for each specimen and each measurement was made in the same center spot.

Calculation for the CIEDE2000 $\left(\Delta \mathrm{E}_{00}\right)$ color difference was performed according to Equation (1) [35,36,45]:

$$
\Delta E_{00}=\left[\left(\frac{\Delta L^{\prime}}{K_{L} S_{L}}\right)^{2}+\left(\frac{\Delta C^{\prime}}{K_{C} S_{C}}\right)^{2}+\left(\frac{\Delta H^{\prime}}{K_{H} S_{H}}\right)^{2}+R_{T}\left(\frac{\Delta C^{\prime}}{K_{C} S_{C}}\right)\left(\frac{\Delta H^{\prime}}{K_{H} S_{H}}\right)\right]^{1 / 2}
$$

For this analysis, the CIEDE2000 color-differences formula in Microsoft Excel (Excel 14.5.7, Mac, Microsoft Corporation, Redmond, DC, USA) was used, as proposed by Sharma et al. [35].

To determine the acceptability and perceptibility thresholds of color change, we used the parameters described by Ghinea et al. in 2010. The color change was clinically acceptable when $\Delta \mathrm{E}_{00}=2.23$ and considered perceptible when $\Delta \mathrm{E}_{00}=1.25$ [34].

\subsection{Translucency Parameter (TP)}

TP values were determined by calculating the color differences against black and white backgrounds for the same specimen, according to the Equation (2) $[38,41,44]$ :

$$
\mathrm{TP}=\left[\left(\Delta \mathrm{L}_{\mathrm{B}}{ }^{*}-\Delta \mathrm{L}_{\mathrm{W}}\right)^{2}+\left(\Delta \mathrm{a}_{\mathrm{B}}{ }^{*}-\Delta \mathrm{a}_{\mathrm{W}}{ }^{*}\right)^{2}+\left(\Delta \mathrm{b}_{\mathrm{B}}{ }^{*}-\Delta \mathrm{b}_{\mathrm{W}^{*}}\right)^{2}\right]^{1 / 2}
$$

where the subscripts $\mathrm{B}$ and $\mathrm{W}$ refer to the color coordinate values obtained against black and white backgrounds, respectively.

\subsection{Contrast Ratio (CR)}

The $C R$ values were calculated from the spectral reflectance $(Y)$ of the specimens with a black $\left(Y_{B}\right)$ and white $\left(Y_{W}\right)$ background as follows in the equation $3[39,44]$ :

$$
\mathrm{CR}=\mathrm{Y}_{\mathrm{B}} / \mathrm{Y}_{\mathrm{W}}
$$

The specimens with $\mathrm{CR}=0.0$ and $\mathrm{CR}=1.0$ were considered transparent and totally opaque materials, respectively [39].

\subsection{Statistical Analysis}

Two-way ANOVA was performed to determine the color change $\left(\Delta \mathrm{E}_{00}\right)$ between materials and treatments, and the Fisher's post hoc test was used for multiple comparisons between groups. Pearson's correlation test was used to analyze the relationship between TP and CR values. A confidence level of $95 \%$ was used in all tests. Statistical analysis was performed with a statistical software program (StatGraphics Centurion XV, StatPoint Technologies, Inc.; Warrenton, VA, USA).

\section{Results}

\subsection{Color Change Evaluation}

The two-way repeated measures ANOVA showed a significant difference $(p<0.05)$ in the color changes $\left(\Delta \mathrm{E}_{00}\right)$ of all tested materials after being immersed in different staining solutions for 30 days. Regarding the stability of the materials tested, $\Delta \mathrm{E}_{00}$ (T3) values showed that PEMA had the highest stability over time, followed by PMMA, PMMA blocks for CAD/CAM, and finally bis-acryl, which obtained the greatest color change (Table 3). 
Table 3. Mean of the color changes $\left(\Delta \mathrm{E}_{00}\right)$ for each material immersed in different staining solutions according to the time (Equation (1)).

\begin{tabular}{cccc}
\hline & \multicolumn{3}{c}{$\Delta \mathrm{E}_{\mathbf{0 0}}$} \\
\cline { 2 - 4 } Material & $\Delta \mathbf{E}_{\mathbf{0 0}}$ (T1) & $\Delta \mathbf{E}_{\mathbf{0 0}}(\mathrm{T} 2)$ & $\Delta \mathbf{E}_{\mathbf{0 0}}$ (T3) \\
& (SD) & $2.88^{\mathrm{c}}(2.30)$ & $5.52^{\mathrm{c}}(4.89)$ \\
\hline Bis-acryl (Structur 3) & $1.82^{\mathrm{c}}(1.42)$ & $2.11^{\mathrm{a}}(1.34)$ & $3.08^{\mathrm{a}}(1.64)$ \\
PEMA (Trim) & $1.08^{\mathrm{a}}(0.87)$ & $2.55^{\mathrm{b}}(1.80)$ & $3.39^{\mathrm{a}}(1.85)$ \\
PMMA (DuraLay) & $1.32^{\mathrm{b}}(1.06)$ & $2.40^{\mathrm{a}, \mathrm{b}}(1.80)$ & $3.83^{\mathrm{b}}(3.51)$ \\
PMMA blocks for CAD/CAM & $1.53^{\mathrm{c}}(1.07)$ & & \\
(Telio CAD) & & & \\
\hline
\end{tabular}

Values with the same uppercase letter do not differ significantly $(p>0.05)$. T1: 24 h; T2: 7 days; T3: 30 days SD: standard deviation. The mean values correspond to 30 specimens per material immersed into six staining solutions with black background.

Regarding the color stability of the groups, Table 4 shows the $\Delta \mathrm{E}_{00}$ black background mean values of each group after $24 \mathrm{~h}$ (T1), 7 days (T2), and 30 days (T3). Furthermore, Figures 2 and 3 show the $\Delta \mathrm{E}_{00}$ black background mean values of each group and staining solution after four weeks (T3). For the PEMA material, the TB group obtained the highest stability after T3 with statistical significance respect to T, TBV, and TV $(p<0.05)$. In the PMMA material, DB had less color changes compared with D, DBV and DV $(p<0.05)$. The PMMA blocks for CAD/CAM showed the highest color stability in the TCB group, with statistical significance $(p<0.05)$, followed by TC, TCBV and TCV. Finally, bis-acryl material obtained the greatest color stability in the S3BV group $(p<0.05)$ followed by S3B and S3V without significant difference, and the S3 group with the least color stability.

Table 4. Mean of color stability $\left(\Delta \mathrm{E}_{00}\right)$ for each group immersed in different staining solutions according to the time (Equation (1)).

\begin{tabular}{|c|c|c|c|c|}
\hline \multirow{2}{*}{ Material } & \multirow{2}{*}{ Groups } & \multicolumn{3}{|c|}{ Mean $\Delta \mathrm{E}_{00}$} \\
\hline & & $\Delta \mathrm{E}_{00} \mathrm{~T} 1$ (SD) & $\Delta \mathrm{E}_{00} \mathrm{~T} 2$ (SD) & $\Delta \mathrm{E}_{00} \mathrm{~T} 3(\mathrm{SD})$ \\
\hline \multirow{4}{*}{ Bis-acryl } & S3 & $1.83^{\mathrm{e}, \mathrm{f}}(1.33)$ & $4.09^{\mathrm{i}}(2.93)$ & $7.41^{\mathrm{i}}(6.15)$ \\
\hline & S3B & $1.67^{\mathrm{d}, \mathrm{e}}(1.31)$ & $2.70^{\mathrm{f}, \mathrm{g}}(1.58)$ & $5.14^{\mathrm{h}}(3.33)$ \\
\hline & S3BV & $1.52^{\mathrm{c}, \mathrm{d}}(1.01)$ & $1.77^{\mathrm{a}, \mathrm{b}}(1.24)$ & $4.42^{\mathrm{e}, \mathrm{f}}(4.48)$ \\
\hline & S3V & $2.24^{\mathrm{g}}(1.85)$ & $2.93^{\mathrm{g}, \mathrm{h}}(2.48)$ & $5.11^{\mathrm{g}, \mathrm{h}}(4.87)$ \\
\hline \multirow{4}{*}{$\begin{array}{c}\text { Polyethyl } \\
\text { methacrylate }\end{array}$} & $\mathrm{T}$ & $1.12^{\mathrm{a}, \mathrm{b}}(0.68)$ & $2.23^{\mathrm{c}, \mathrm{d}, \mathrm{e}}(0.98)$ & $3.30^{b, c}(1.08)$ \\
\hline & $\mathrm{TB}$ & $0.86^{\mathrm{a}}(0.39)$ & $1,74^{\mathrm{a}}(1.08)$ & $2,54^{\mathrm{a}}(1.01)$ \\
\hline & TBV & $1.35^{\mathrm{b}, \mathrm{c}}(1.16)$ & $2.33^{\mathrm{d}, \mathrm{e}, \mathrm{f}}(1.13)$ & $3.18^{b, c}(1.83)$ \\
\hline & $\mathrm{TV}$ & 0.99 a,b (1.01) & $2.13^{b, c, d, e}(1.94)$ & $3.31^{b, c}(2.24)$ \\
\hline \multirow{4}{*}{$\begin{array}{l}\text { Polymethyl } \\
\text { methacrylate }\end{array}$} & $\mathrm{D}$ & $1.13^{\mathrm{a}, \mathrm{b}}(0.65)$ & $2.00^{\mathrm{a}, \mathrm{b}, \mathrm{c}, \mathrm{d}}(0.56)$ & $2.88^{a, b}(1.02)$ \\
\hline & $\mathrm{DB}$ & $1.06^{\mathrm{a}}(0.56)$ & $1.89^{\mathrm{a}, \mathrm{b}, \mathrm{c}}(0.55)$ & $2.51^{\mathrm{a}}(0.77)$ \\
\hline & DBV & $1.57^{\mathrm{c}, \mathrm{d}, \mathrm{e}}(1.35)$ & $3.03^{\mathrm{g}, \mathrm{h}}(1.63)$ & $3.94^{\mathrm{d}, \mathrm{e}}(1.91)$ \\
\hline & DV & $1.50^{\mathrm{c}, \mathrm{d}}(1.35)$ & 3.29 h $(2.90)$ & $4.22^{\mathrm{d}, \mathrm{e}, \mathrm{f}}(2.58)$ \\
\hline \multirow{4}{*}{$\begin{array}{l}\text { Polymethyl } \\
\text { methacrylate } \\
\text { blocks for } \\
\text { CAD/CAM }\end{array}$} & $\mathrm{TC}$ & $0.91^{\mathrm{a}}(0.62)$ & $2.45^{\mathrm{e}, \mathrm{f}}(2.25)$ & $3.86^{\mathrm{d}}(3.71)$ \\
\hline & TCB & $1.03^{\mathrm{a}}(0.70)$ & $1.72^{\mathrm{a}}(1.15)$ & $3.20^{b, c}(3.27)$ \\
\hline & TCBV & $1.99^{\mathrm{f}, \mathrm{g}}(1.16)$ & $2.32 \mathrm{~d}, \mathrm{e}, \mathrm{f}(1.63)$ & $3.70^{\mathrm{c}, \mathrm{d}}(3.29)$ \\
\hline & $\mathrm{TCV}$ & $2.18^{g}(1.10)$ & $3.11^{\mathrm{h}}(1.80)$ & $4.59^{\mathrm{f}, \mathrm{g}}(3.78)$ \\
\hline
\end{tabular}

Values with the same lower case superscript letters within column denote groups whose color does not differ significantly for each staining solution $(p>0.05)(a=$ low staining and $\mathrm{i}=$ high staining). The method used to discriminate among the means is Fisher's least significant difference (LSD). T1: 24 h; T2: 7 days; T3: 30 days. SD: standard deviation. Letter $B$ in the groups denote brushing process and groups with letter $V$ indicate varnish application. The mean values correspond to five specimens per group immersed in six staining solutions with black background. 

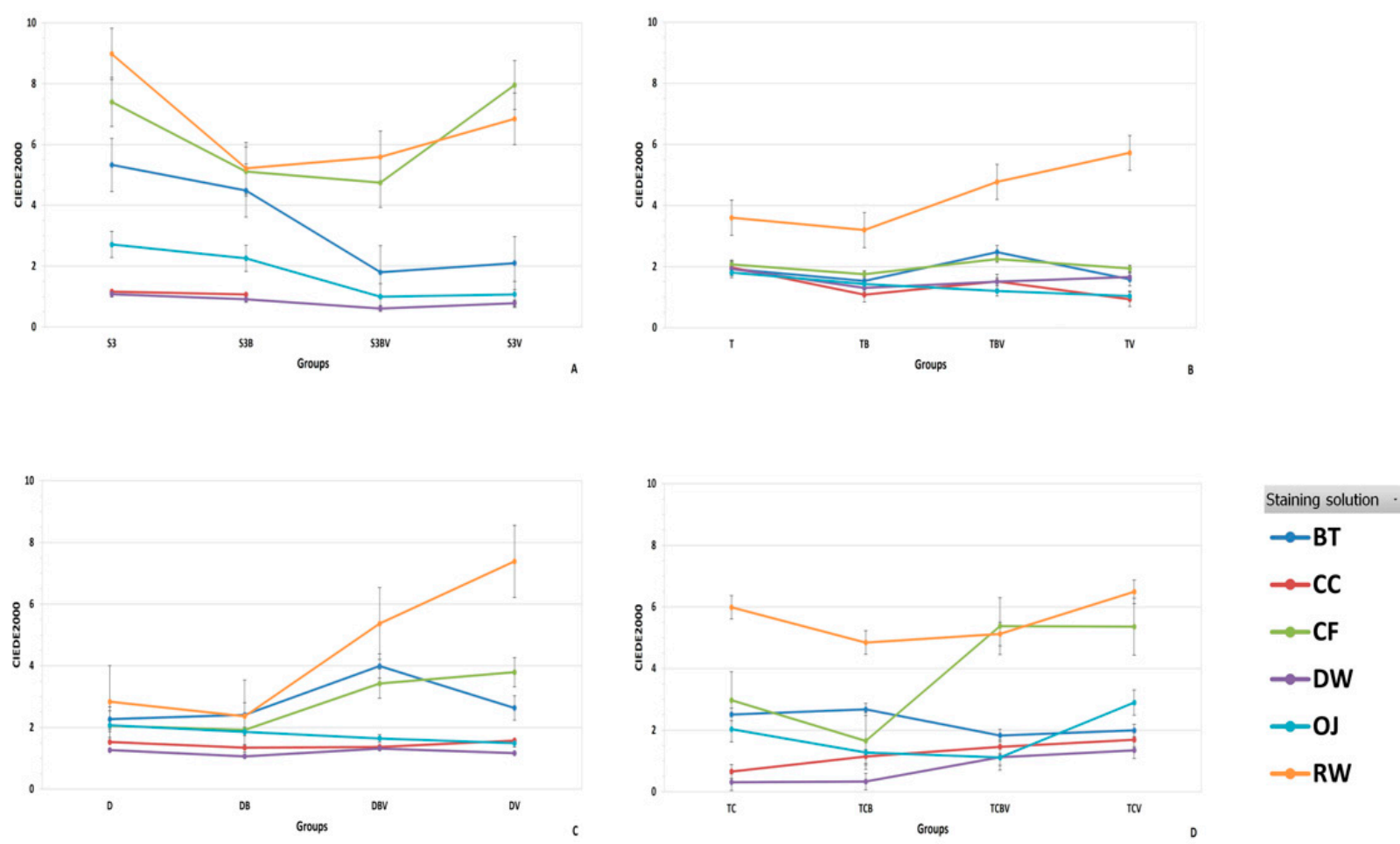

Figure 2. Mean $\Delta \mathrm{E}_{00}$ (T1, T2, and T3) interaction for each group and different staining solution: (A) bis-acryl (Structur 3); (B) PEMA (Trim); (C) PMMA (DuraLay); and (D) PMMA blocks for CAD/CAM (TelioCAD).
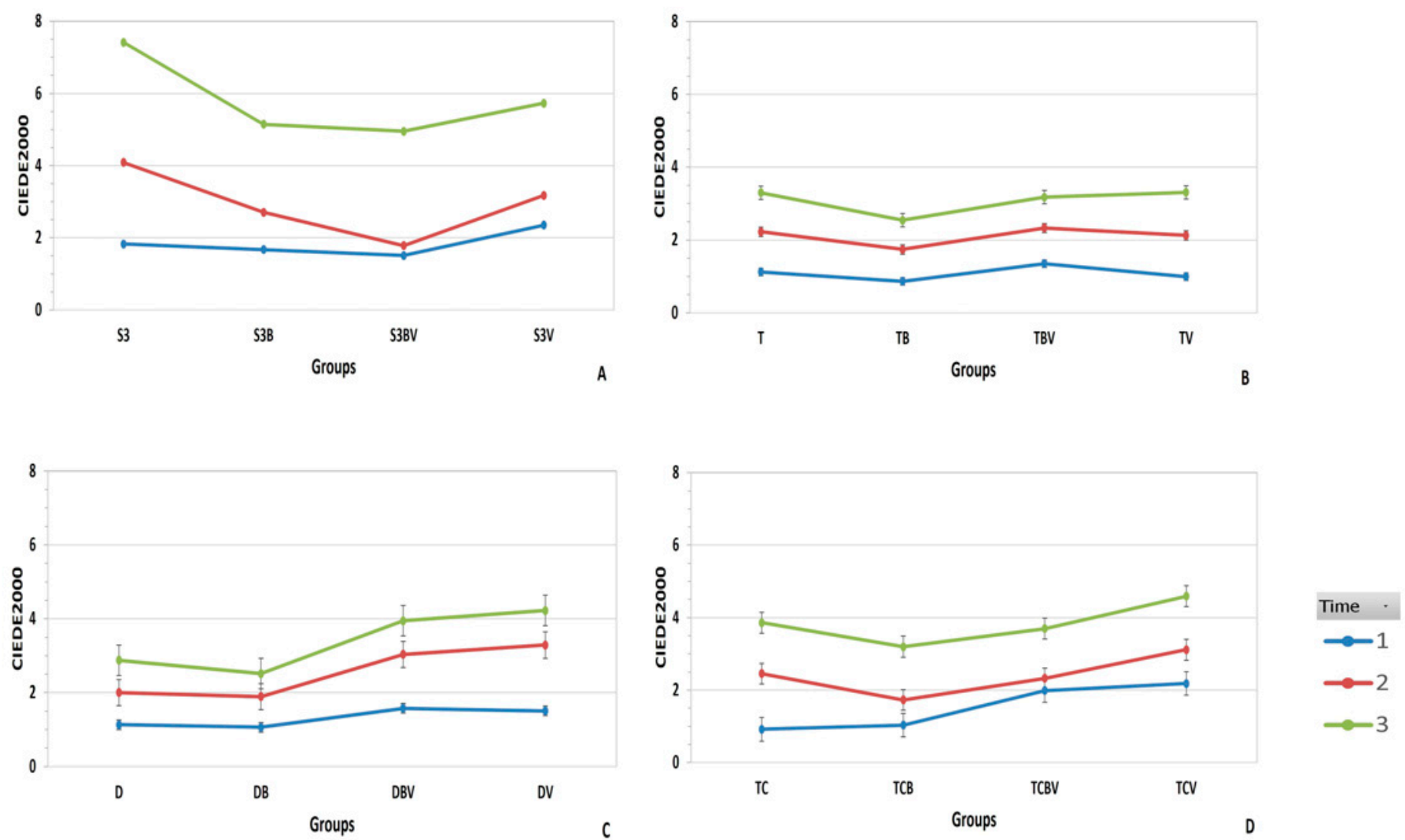

Figure 3. Mean $\Delta \mathrm{E}_{00}$ (six staining solutions) interaction for each group and time: $\mathrm{T} 1$ (24 h); T2 (7 days); T3 (30 days). (A) bis-acryl (Structur 3); (B) PEMA (Trim); (C) PMMA (DuraLay); and (D) PMMA blocks for CAD/CAM (TelioCAD). 
For the different groups evaluated, the highest staining potential values were observed in the red wine solution followed by coffee, black tea, orange juice, Coca-Cola, and distilled water $(p<0.05)$ (Figure 2).

When each group was analyzed with a clinical perceptibility threshold (PT) and clinical acceptability threshold (AT), the results showed that in the first day (T1) TB, TC, $\mathrm{TV}, \mathrm{TCB}, \mathrm{DB}, \mathrm{T}$, and $\mathrm{D}$ groups were in the PT $\left(\Delta \mathrm{E}_{00}=0.91-1.13\right)$, while the other groups maintained AT within a range of $\Delta \mathrm{E}_{00}=1.83-2.23$.

In T2 (7 days), all the groups were above PT. However, TCB, TB, S3BV, DB, D, and TV groups maintained AT with a range of $\Delta \mathrm{E}_{00}=1.72-2.13$. Finally, in T3 (30 days), all the groups were out of the threshold.

\subsection{Translucency Parameter and Contrast Ratio}

The mean translucency values measured by TP and CR were statistically significant $(p<0.05)$. These methods showed a strong correlation $\left(\mathrm{r}^{2}=0.96\right)$, as seen in Table 5 .

Table 5. Mean of initial (T0) translucency parameter (TP) and contrast ratio (CR) by material.

\begin{tabular}{ccc}
\hline Material & TP (SD) & CR (SD) \\
\hline Bis-acryl & $15.45^{\mathrm{d}}(0.78)$ & $1.40^{\mathrm{d}}(0.02)$ \\
PEMA & $11.70^{\mathrm{b}}(1.39)$ & $1.34^{\mathrm{b}}(0.05)$ \\
PMMA & $7.14^{\mathrm{a}}(0.57)$ & $1.22^{\mathrm{a}}(0.03)$ \\
PMMA blocks for CAD/CAM & $13.37^{\mathrm{c}}(0.63)$ & $1.38^{\mathrm{c}}(0.03)$ \\
\hline
\end{tabular}

Different letters show statistical differences of mean values within the parameter (column) $(p<0.05)$; Fisher's least significant difference. SD: standard deviation.

\section{Discussion}

The first null hypothesis of the study was partly accepted because the CAD/CAM blocks had a color-difference from some conventional materials (PEMA and bis-acryl) after immersion in staining solutions for four weeks. The second null hypothesis was accepted but should be analyzed separately regarding varnish and brushing.

In this study, four materials were used (PEMA, PMMA, PMMA blocks for CAD/CAM, and bis-acryl); each material was divided into four groups, which were exposed to different surface treatments and immersed in six staining solutions. The color values were analyzed by using CIEDE2000 but to our knowledge, no studies exist comparing the color stability of PMMA blocks for CAD/CAM with conventional interim materials with and without varnish and brushing.

To analyze the color stability in the present study, we accounted for perceptibility (PT) and acceptability (AT) thresholds 50:50\% published in 2010, which uses TSK Fuzzy Approximation in preference to an S-shaped curve due to the slightly higher accuracy of the former. The perceptibility threshold was $\Delta \mathrm{E}_{00}=1.25\left(\mathrm{r}^{2}=0.89\right)$ and the acceptability threshold was $2.23\left(\mathrm{r}^{2}=0.89\right)$ [34]. In the present study, it was found that all materials values in the first day (T1) were within the parameters of acceptability, however, the bisacryl material was slightly higher $(p<0.05)$. From seven days (T2) the mean value showed that all materials were above the acceptability threshold $\left(\Delta \mathrm{E}_{00}>2.23\right)$, except the PEMA which obtained $\Delta \mathrm{E}_{00}=2.11(p<0.05)$. Ertaş et al. [12] suggest that $24 \mathrm{~h}$ of immersion simulates about one month of consumption. Therefore, the values of the present study in $\mathrm{T} 1, \mathrm{~T} 2$, and T3 should be equivalent to 1, 7, and 30 months, respectively, in vivo.

Staining is a common problem for all restorative materials after long-term use [46]. Changes in the optical properties have been attributed to the oxidation of the polymer matrix or oxidation of unreacted double bonds in the residual monomers [7]. The results of the present study are in agreement with the others showing high color stability for PEMA materials after 30 days of immersion [13] and the least color stability in bis-acryl materials after immersion in coffee solution [7]. Furthermore, the present findings accord with those of studies where more color stability was obtained in PMMA than in bis-acryl materials [4,47]. 
The color stability of organic molecules is related to their capacity to absorb light into energy levels involving molecular orbitals, which are generally based on covalent chemical bonding in a conjugated system of alternating single and double bonds, which may have attached to it electron donor and acceptor groups [48]. Exogenous and endogenous factors decompose the original molecular structure and organization, disturbing the color stability of the material.

In common with other studies, red wine caused the most staining in all experimental groups, followed by coffee, black tea, orange juice, Coca-Cola, and distilled water [12]. In spite of Coca-Cola having the lowest $\mathrm{pH}$, which might modify the material surface, in the present study it did not have a stainability as high as other solutions such as black tea, coffee, and orange juice [12]. According to Um et al. [14], solutions such as tea and coffee contain yellow colorants, which have different polarities (higher polarity for tea and lower polarity for coffee). The materials immersed in coffee solutions pigmented more than tea because the lower polarity of the solution promotes a high penetration of pigments into the organic phase due to adsorption and absorption processes, whereas solutions with high polarity such as tea do not penetrate easily into the materials, and therefore the pigments can be removed by tooth brushing.

These results are at odds with the suggestions of Dede et al. [23] and Doray et al. [24] who found better results applying the surface varnish because it improved the staining resistances of the interim materials. Similarly to the works of some authors, the present study found that when varnish was applied, the values of color stability exceeded the clinical acceptability parameter $\left(\Delta \mathrm{E}_{00}>2.23\right)[49,50]$, probably because, as explained by some authors, surface varnish tends to separate and degrade with tooth brushing [26,27].

Regarding the effect of tooth brushing on the color stability of materials, the present study found better color stability with interim materials such as other authors who brushed their specimens, because some absorbed colorants or surface staining can be removed by tooth brushing $[45,51]$.

Although the Telio CAD is a PMMA block without filler content, and it is possible to create abrasions during brushing, resulting in increased roughness [52], the results described in the present study regarding color stability are favorable.

Finally, to evaluate the translucency parameter (TP) and contrast ratio (CR), in the literature there are no data with optimal or acceptable TP values for dental materials. However, Paravina et al. [38] suggest dividing the TP range into low translucency (TP $=2.0-3.7)$, medium translucency $(\mathrm{TP}=3.8-5.4)$, and high translucency $(\mathrm{TP}>5.5)$. The results of the present study showed a high TP in all materials evaluated (range TP = 7.14-15.45), with significant differences of translucency $(p<0.05)$. Considering the TP and CR of interim materials, we agree with the consensus in the literature on when an aesthetic interim restoration is necessary; to hide the background, the restoration should be made with a greater thickness $[42,43]$. As in previous studies, TP and CR were strongly correlated; when TP decreases CR increases $\left(\mathrm{r}^{2}=0.96\right)[39,43]$.

The effect of absorption influence and roughness parameters on color stability should be evaluated in future studies.

\section{Conclusions}

Within the limitations of this in vitro study, the following conclusions were drawn:

PEMA had the highest stability over time, followed by PMMA, PMMA blocks for CAD/CAM, and finally bis-acryl, which obtained the greatest color change.

From seven days of immersion, the mean value showed that PMMA, PMMA blocks for CAD/CAM, and finally bis-acryl materials were above the clinical acceptability threshold.

The lower staining values were presented in groups with brushing when compared with the other groups $(p<0.05)$.

The varnish does not reduce the color stainability of materials with different compositions, such as PEMA, PMMA, and PMMA blocks for CAD/CAM. It was more favorable in bis-acryl material. 
TP and CR showed a strong correlation for all the interim materials evaluated.

Author Contributions: Conceptualization, L.P., J.B. and M.M.; methodology, L.P., and M.A.; formal analysis, L.P. and R.C.; investigation, L.P.; resources, L.P. and J.B.; writing-original draft preparation, L.P. and M.A.; writing-review and editing, M.M., J.B., M.R. and R.C.; supervision, M.M., M.R. and J.B. All authors have read and agreed to the published version of the manuscript.

Funding: This research received no external funding.

Institutional Review Board Statement: Not applicable.

Informed Consent Statement: Not applicable.

Acknowledgments: The authors acknowledge their gratitude to Ivoclar Vivadent and VOCO for their support with the materials used in this study. Additionally, we would like to express our sincere thanks to Jessica Elizondo and Anabella Paolini for their valuable support in the research project during their University Master's Degree in Aesthetic Restorative Dentistry.

Conflicts of Interest: The authors declare no conflict of interest.

\section{References}

1. Bayindir, F.; Kürklü, D.; Yanikoğlu, N.D. The effect of staining solutions on the color stability of provisional prosthodontic materials. J. Dent. 2012, 40, e41-e46. [CrossRef] [PubMed]

2. Imirzalioglu, P.; Karacaer, O.; Yilmaz, B.; Ozmen Msc, I. Color stability of denture acrylic resins and a soft lining material against tea, coffee, and nicotine. J. Prosthodont. 2010, 19, 118-124. [CrossRef] [PubMed]

3. Eisenburger, M.; Riechers, J.; Borchers, L.; Stiesch-Scholz, M. Load-bearing capacity of direct four unit provisional composite bridges with fibre reinforcement. J. Oral Rehabil. 2008, 35, 375-381. [CrossRef] [PubMed]

4. Givens, E.J., Jr.; Neiva, G.; Yaman, P.; Dennison, J.B. Marginal adaptation and color stability of four provisional materials. J. Prosthodont. 2008, 17, 97-101. [CrossRef]

5. Balkenhol, M.; Mautner, M.C.; Ferger, P.; Wöstmann, B. Mechanical properties of provisional crown and bridge materials: Chemical-curing versus dual-curing systems. J. Dent. 2008, 36, 15-20. [CrossRef]

6. Burns, D.R.; Beck, D.A.; Nelson, S.K.; Committee on Research in Fixed Prosthodontics of the Academy of Fixed Prosthodontics. A review of selected dental literature on contemporary provisional fixed prosthodontic treatment: Report of the Committee on Research in Fixed Prosthodontics of the Academy of Fixed Prosthodontics. J. Prosthet. Dent. 2003, 90, 474-497. [CrossRef]

7. Sham, A.S.; Chu, F.C.; Chai, J.; Chow, T.W. Color stability of provisional prosthodontic materials. J. Prosthet. Dent. 2004, 91, 447-452. [CrossRef]

8. Arocha, M.A.; Basilio, J.; Llopis, J.; Di Bella, E.; Roig, M.; Ardu, S.; Mayoral, J.R. Color stainability of indirect CAD/CAM processed composites vs. conventionally laboratory processed composites after immersion in staining solutions. J. Dent. 2014, 42 , 831-838. [CrossRef]

9. Stawarczyk, B.; Sener, B.; Trottmann, A.; Roos, M.; Ozcan, M.; Hämmerle, C.H. Discoloration of manually fabricated resins and industrially fabricated CAD/CAM blocks versus glass-ceramic: Effect of storage media, duration, and subsequent polishing. Dent. Mater. J. 2012, 31, 377-383. [CrossRef]

10. Kolbeck, C.; Rosentritt, M.; Lang, R.; Handel, G. Discoloration of facing and restorative composites by UV-irradiation and staining food. Dent. Mater. 2006, 22, 63-68. [CrossRef]

11. Ardu, S.; Gutemberg, D.; Krejci, I.; Feilzer, A.J.; Di Bella, E.; Dietschi, D. Influence of water sorption on resin composite color and color variation amongst various composite brands with identical shade code: An in vitro evaluation. J. Dent. 2011, 39, e37-e44. [CrossRef]

12. Ertaş, E.; Güler, A.U.; Yücel, A.C.; Köprülü, H.; Güler, E. Color stability of resin composite after immersion in different drinks. Dent. Mater. J. 2006, 25, 371-376. [CrossRef]

13. Scotti, R.; Mascellani, S.C.; Forniti, F. The in vitro color stability of acrylic resins for provisional restorations. Int. J. Prosthodont. 1997, 10, 164-168.

14. Um, C.M.; Ruyter, I.E. Staining of resin-based veneering materials with coffee and tea. Quintessence Int. 1991, $22,377-386$.

15. Crispin, B.J.; Caputo, A.A. Color stability of temporary restorative materials. J. Prosthet. Dent. 1979, 42, 27-33. [CrossRef]

16. Alt, V.; Hannig, M.; Wöstmann, B.; Balkenhol, M. Fracture strength of temporary fixed partial dentures: CAD/CAM versus directly fabricated restorations. Dent. Mater. 2011, 27, 339-347. [CrossRef]

17. Vallittu, P.K. The effect of glass fiber reinforcement on the fracture resistance of a provisional fixed partial denture. J. Prosthet. Dent. 1998, 79, 125-130. [CrossRef]

18. Stawarczyk, B.; Basler, T.; Ender, A.; Roos, M.; Ozcan, M.; Hämmerle, C. Effect of surface conditioning with airborne-particle abrasion on the tensile strength of polymeric CAD/CAM crowns luted with self-adhesive and conventional resin cements. J. Prosthet. Dent. 2012, 107, 94-101. [CrossRef] 
19. Peñate, L.; Basilio, J.; Roig, M.; Mercadé, M. Comparative study of interim materials for direct fixed dental prostheses and their fabrication with CAD/CAM technique. J. Prosthet. Dent. 2015, 114, 248-253. [CrossRef]

20. Da Costa, J.; Adams-Belusko, A.; Riley, K.; Ferracane, J.L. The effect of various dentifrices on surface roughness and gloss of resin composites. J. Dent. 2010, 38, 123-128. [CrossRef]

21. Jassé, F.F.; De Campos, E.A.; Lefever, D.; Di Bella, E.; Salomon, J.P.; Krejci, I.; Ardu, S. Influence of filler charge on gloss of composite materials before and after in vitro toothbrushing. J. Dent. 2013, 41, e41-e44. [CrossRef] [PubMed]

22. Lefever, D.; Perakis, N.; Roig, M.; Krejci, I.; Ardu, S. The effect of toothbrushing on surface gloss of resin composites. Am. J. Dent. 2012, 25, 54-58. [PubMed]

23. Dede, D.Ö.; Şahin, O.; Köroğlu, A.; Yilmaz, B. Effect of sealant agents on the color stability and surface roughness of nanohybrid composite resins. J. Prosthet. Dent. 2016, 116, 119-128. [CrossRef] [PubMed]

24. Doray, P.G.; Eldiwany, M.S.; Powers, J.M. Effect of resin surface sealers on improvement of stain resistance for a composite provisional material. J. Esthet. Restor. Dent. 2003, 15, 244-249. [CrossRef] [PubMed]

25. Thompson, G.A.; Luo, Q. Contribution of postpolymerization conditioning and storage environments to the mechanical properties of three interim restorative materials. J. Prosthet. Dent. 2014, 112, 638-648. [CrossRef]

26. Santos, M.; Soo, S.; Petridis, H. The effect of Parylene coating on the surface roughness of PMMA after brushing. J. Dent. 2013, 41, 802-808. [CrossRef]

27. Zimmerli, B.; Koch, T.; Flury, S.; Lussi, A. The influence of toothbrushing and coffee staining on different composite surface coatings. Clin. Oral. Investig. 2012, 16, 469-479. [CrossRef]

28. Köroğlu, A.; Şahin, O.; Dede, D.Ö.; Yilmaz, B. Effect of different surface treatment methods on the surface roughness and color stability of interim prosthodontic materials. J. Prosthet. Dent. 2016, 115, 447-455. [CrossRef]

29. Zhao, X.; Pan, J.; Malmstrom, H.S.; Ren, Y.F. Protective effects of resin sealant and flowable composite coatings against erosive and abrasive wear of dental hard tissues. J. Dent. 2016, 49, 68-74. [CrossRef]

30. Ardu, S.; Feilzer, A.J.; Devigus, A.; Krejci, I. Quantitative clinical evaluation of esthetic properties of incisors. Dent. Mater. 2008, 24, 333-340. [CrossRef]

31. Okubo, S.R.; Kanawati, A.; Richards, M.W.; Childress, S. Evaluation of visual and instrument shade matching. J. Prosthet. Dent. 1998, 80, 642-648. [CrossRef]

32. Johnston, W.M. Color measurement in dentistry. J. Dent. 2009, 37s, e2-e6. [CrossRef]

33. Perez, M.M.; Ghinea, R.; Herrera, L.J.; Ionescu, A.M.; Pomares, H.; Pulgar, R.; Paravina, R.D. Dental ceramics: A CIEDE2000 acceptability thresholds for lightness, chroma and hue differences. J. Dent. 2011, 39, e37-e44. [CrossRef]

34. Ghinea, R.; Pérez, M.M.; Herrera, L.J.; Rivas, M.J.; Yebra, A.; Paravina, R.D. Color difference thresholds in dental ceramics. J. Dent. 2010, 38, e57-e64. [CrossRef]

35. Sharma, G.; Wu, W.; Dalal, E.N. The CIEDE2000 color-difference formula: Implementation notes, supplementary test data, and mathematical observations. Color Res. Appl. 2005, 30, 21-30. [CrossRef]

36. CIE Technical Report: Improvement to Industrial Color-Difference Evaluation; CIE pub No. 142; Central Bureau: Vienna, Austria, 2001.

37. Lee, Y.K. Comparison of CIELAB $\Delta E^{*}$ and CIEDE2000 color-differences after polymerization and thermocycling of resin composites. Dent. Mater. 2005, 21, 678-682. [CrossRef]

38. Paravina, R.D.; Ontiveros, J.C.; Powers, J.M. Curing-dependent changes in color and translucency parameter of composite bleach shades. J. Esthet. Restor. Dent. 2002, 14, 158-166. [CrossRef]

39. Della Bona, A.; Nogueira, A.D.; Pecho, O.E. Optical properties of CAD/CAM ceramic systems. J. Dent. 2014, 42, 1202-1209. [CrossRef]

40. Johnston, W.M. Review of translucency determinations and applications to dental materials. J. Esthet. Restor. Dent. 2014, 26, 217-223. [CrossRef]

41. Johnston, W.M.; Ma, T.; Kienle, B.H. Translucency parameter of colorants for maxillofacial prostheses. Int. J. Prosthodont. 1995, 8, 79-86.

42. Miyagawa, Y.; Powers, J.M.; O’Brien, W.J. Optical properties of direct restorative materials. J. Dent. Res. 1981, 60, 890-894. [CrossRef] [PubMed]

43. Powers, J.M.; Dennison, J.B.; Lepeak, P.J. Parameters that affect the color of direct restorative resins. J. Dent. Res. 1978, 57, 876-880. [CrossRef] [PubMed]

44. Yu, B.; Ahn, J.S.; Lee, Y.K. Measurement of translucency of tooth enamel and dentin. Acta Odontol. Scand. 2009, 67, 57-64. [CrossRef] [PubMed]

45. CIE. Technical Report: Colorimetry, 3rd ed.; CIE pub No. 15; Central Bureau: Vienna, Austria, 2004.

46. Bezgin, T.; Özer, L.; Tulga Öz, F.; Özkan, P. Effect of toothbrushing on color changes of esthetic restorative materials. J. Esthet. Restor. Dent. 2015, 27, S65-S73. [CrossRef]

47. Guler, A.U.; Kurt, S.; Kulunk, T. Effects of various finishing procedures on the staining of provisional restorative materials. J. Prosthet. Dent. 2005, 93, 453-458. [CrossRef]

48. Nassau, K. The Physics and Chemistry of color. In The Fifteen Causes of Color; John Wiley \& Sons, Inc.: Hoboken, NJ, USA, 1983; p. 138.

49. Lee, Y.K.; Powers, J.M. Combined effects of staining substances on resin composites before and after surface sealant application. J. Mater. Sci. Mater. Med. 2007, 18, 685-691. [CrossRef] 
50. Valentini, F.; Oliveira, S.G.; Guimarães, G.Z.; Barbosa, R.P.; Moraes, R.R. Effect of surface sealant on the color stability of composite resin restorations. Braz. Dent. J. 2011, 22, 365-368. [CrossRef]

51. Ren, Y.F.; Feng, L.; Serban, D.; Malmstrom, H.S. Effects of common beverage colorants on color stability of dental composites resins: The utility of a thermocycling stain challenge model in vitro. J. Dent. 2012, 40, e48-e56. [CrossRef]

52. Kamonkhantikul, K.; Arksornnukit, M.; Lauvahutanon, S.; Takahashi, H. Toothbrushing alters the surface roughness and gloss of composite resin CAD/CAM blocks. Dent. Mater. J. 2016, 35, 225-232. [CrossRef] 